\title{
Hereditary thoracic aortic disease: How to save lives
}

Mary J. Roman, $\mathrm{MD},{ }^{\mathrm{a}}$ and Julie De Backer, $\mathrm{MD}, \mathrm{PhD}^{\mathrm{b}}$

Aortic dissection, particularly that involving the ascending aorta, remains an important (and underestimated) cause of sudden death. ${ }^{1}$ If aneurysmal dilatation preceding dissection is unrecognized, the availability of preventive elective aortic replacement is moot. In contrast, known aneurysms can be managed with aggressive blood pressure control and lifestyle interventions, monitored with serial imaging, and electively replaced with low surgical morbidity and mortality when the risk of dissection rises. Thus, timely detection of aortic aneurysms is paramount in reducing dissection risk. Aneurysms may be detected incidentally, for example, when an imaging study is performed for an unrelated reason, or when suspected based on the presence of syndromic features of a genetic aortopathy, such as those associated with Marfan syndrome or Loeys-Dietz syndrome.

The importance of family history in determining the risk for aortic aneurysm and dissection, and hence genetic predisposition, is reinforced by 2 recent simultaneous publications that provide population-based estimates of dissection risk when a first-degree relative has suffered an aortic dissection. ${ }^{2,3}$ The Taiwan study ${ }^{2}$ was based on data from its National Health Insurance Program that covers over $99 \%$ of the population. Almost 24,000 incident dissections occurred between 2000 and 2015 . The overall relative risk for aortic dissection was 6.82 in first-degree relatives and remained high (5.05) after elimination of syndromic conditions. Genetic factors accounted for $57 \%$ of phenotypic variability. Of note, dissection prevalence was 2- to 3-fold higher in men than in women independent of family history.

The Danish study, performed in another country with universal health care, used registries to identify individuals with aortic aneurysms and dissections. ${ }^{3}$ Over an average 7-year follow-up, first-degree relatives of these individuals had a hazard ratio (HR) of 6.7 for aneurysm and 9.24 for dissection compared with matched controls. Findings remained significant after exclusion of individuals with Marfan syndrome, bicuspid aortic valve, or hypertension. As in

\footnotetext{
From the ${ }^{\mathrm{a}}$ Division of Cardiology, Department of Medicine, Weill Cornell Medicine, New York, NY and ${ }^{\mathrm{b}}$ Department of Cardiology and Center for Medical Genetics, Ghent University Hospital, Ghent, Belgium.

Received for publication Dec 11, 2020; revisions received Jan 6, 2021; accepted for publication Jan 14, 2021; available ahead of print Feb 2, 2021.

Address for reprints: Mary J. Roman, MD, Weill Cornell Medicine, 520 East 70th St,

New York, NY (E-mail: mroman@med.cornell.edu).

J Thorac Cardiovasc Surg 2022;163:39-45

$0022-5223 / \$ 36.00$

Copyright (c) 2021 by The American Association for Thoracic Surgery

https://doi.org/10.1016/j.jtcvs.2021.01.075
}

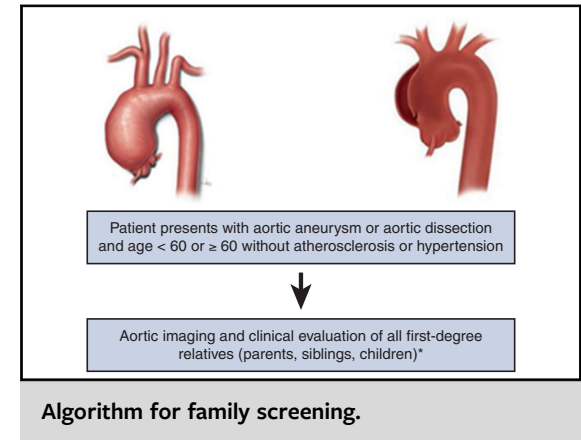

CENTRAL MESSAGE

Aortic aneurysms and dissections may be due to a heritable aortopathy. Screening of firstdegree relatives can result in timely referral for elective aortic surgery. Family screening saves lives.

This Invited Expert Opinion provides a perspec tive on the following paper: J Am Coll Cardiol. 2020;76(10):1181-1192. https://doi.org/10.1016/j.jacc 2020.07 .028

See Commentaries on pages 46,47 , and 48 .

the Taiwan study, male sex was associated with an HR of 2.2 for aneurysm and 1.72 for aortic dissection. In a separate analysis, the authors compared aortic diameters measured by computed tomography scan in parents and offspring in the Framingham Heart Study. The risk of an aortic diameter falling in the highest quartile in an offspring was increased by 2 - to 3 -fold, depending on the aortic level, if at least one parent had such a finding. ${ }^{3}$

The strength of both studies lies in the use of robust population-based data to quantify rates of aortic dissection, although individuals who die before hospitalization obviously are not captured. Unfortunately, neither study subdivided dissection according to location. However, to the extent that descending and abdominal dissections are less likely than those involving the ascending aorta to be genetically mediated, family association will only be underestimated. In contrast, aneurysm detection and prevalence estimates are more problematic in the absence of systematic screening, known age-dependent expression, variations in 
measurement location and technique, and the need to account for the importance of age, sex, and body size in defining aneurysmal dilatation. Finally, given the nature of the study design, genetic data were not available.

In broad terms, hereditary thoracic aortic disease (HTAD; other terms for this condition include familial thoracic aortic aneurysm and dissection [FTAAD] and genetic aortopathy) can be classified as syndromic or nonsyndromic, based on the respective presence or absence of extraaortic manifestations. Although neither of the 2 recent population-based studies provided direct genetic data and both likely underrecognized syndromic conditions, it can be reasonably inferred that most of the familial clustering represented non-syndromic HTAD. Although the presence of Marfan syndrome or bicuspid aortic valve greatly increased the risk for aortic dissection (HR, 65.71 for Marfan syndrome and 16.33 for bicuspid aortic valve in the Danish study; relative risk, 31.92 for Marfan syndrome and 5.88 for bicuspid aortic valve in the Taiwan study), these groups constituted a small minority of the populations. Unfortunately, owing to the usual absence of nonaortic phenotypic features, nonsyndromic HTAD is more likely to present with aortic dissection in the proband. ${ }^{4,5}$

To the extent that early recognition may not be a feasible strategy, particularly in nonsyndromic families, the "second line" of defense falls on healthcare providers treating those with known aneurysms and dissections, particularly cardiologists and cardiothoracic surgeons. A proband is the first member of a family in whom HTAD is detected and should serve as the stimulus for genetic diagnostics in the patient in parallel with screening of first-degree relatives. HTAD is inherited in an autosomal dominant manner; however, nonsyndromic types may have variable penetrance, especially in females, ${ }^{6}$ and age-dependent expression. Spontaneous variants account for approximately $25 \%$ of patients with Marfan syndrome $^{7}$; spontaneous variant rates in other conditions are not well characterized.

Because HTAD dissections usually occur earlier than those associated with hypertension and atherosclerosis, genetic testing is more likely to be informative when the proband is young (age $<60$ years). ${ }^{8}$ However, before concluding that a degenerative cause is present in an older individual, one must ensure that the patient does not have syndromic features and that familial involvement is not present. Preventive screening with dedicated imaging for aneurysm in all first-degree relatives should be undertaken (Figure 1). Because aneurysm expression may be agedependent, an initial normal imaging study should be repeated in 5 years. ${ }^{8}$ If a pathogenic variant is identified in the proband and absent in a first-degree relative with a normal initial imaging study at screening, further surveillance imaging can be discontinued. A comprehensive list of genes implicated in HTAD is provided in Table 1. An appreciation of the potential phenotypic features in these families is equally critically important.

The major syndromic aortopathies may be diagnosed or strongly suspected based on clinical features, with confirmation by detection of a monogenic pathogenic variant (Table 2). Diagnostic criteria for the prototypical Marfan syndrome have been established ${ }^{9}$; cardinal features include the presence of aortic root dilatation and ectopia lentis. If one of these cardinal features is absent, then the diagnosis requires definite family history or a (likely) pathogenic variant in the gene coding for fibrillin 1 (FBN1), or a high systemic score $(\geq 7)$ based on the weighted presence of characteristic phenotypic features (ie, arachnodactyly, pectus deformity, hind foot deformity, spontaneous pneumothorax, dural ectasia, scoliosis, striae, dolichocephaly [typical facies], severe myopia, and mitral valve prolapse). Bedside application of diagnostic criteria is greatly facilitated by use of the smartphone app Marfan Dx, which is also available on the Marfan Foundation website (https:// www.marfan.org/dx/home).

Medical management of Marfan syndrome includes treatment with beta blockers or angiotensin receptor blockers to reduce the rate of aortic growth, ${ }^{10}$ avoidance of contact and competitive sports and isometric forms of exercise to decrease dissection risk, surveillance imaging, and timely referral for elective aortic root replacement. In the absence of rapid growth (3-5 $\mathrm{mm}$ per year) or a family history of aortic dissection at a small aortic diameter, a threshold of $5.0 \mathrm{~cm}$ for surgical referral is recommended. ${ }^{11}$ Safe and effective replacement of the ascending aorta has made type $\mathrm{B}$ dissection more common than type A dissection in patients receiving optimal management. ${ }^{11}$ Type B dissections may occur more commonly after elective root replacement, ${ }^{12}$ possibly owing to altered flow dynamics related to the rigid proximal conduit or to a more severe phenotype. Analyses of genotype-phenotype correlations indicate that individuals with variants that lead to haploinsufficiency have a more severe aortic phenotype than those resulting in a dominant negative effect. ${ }^{13}$

Loeys-Dietz syndrome was recognized as a separate HTAD in 2005 with overlapping phenotypic features of Marfan syndrome (other than ectopia lentis) but with several distinguishing characteristics. ${ }^{14}$ The initial description attributed the syndrome to mutations in transforming growth factor (TGF) $\beta$ receptors (TGFBR1 and TGFBR2) resulting in abnormal TGF- $\beta$ signaling. Subsequently, additional genes coding for TGF- $\beta$ ligands (TGFB2 and TGFB3) and intracellular components (SMAD2 and $S M A D 3$ ) of the TGF- $\beta$ signaling pathway have been added as causes of the Loeys-Dietz phenotype. ${ }^{15}$ Additional bedside or historical diagnostic features include hypertelorism (widely spaced eyes), bifid uvula, cleft palate, and clubfoot. Patients with SMAD3 mutations may have an additional syndromic feature of early-onset osteoarthritis. ${ }^{16}$ 

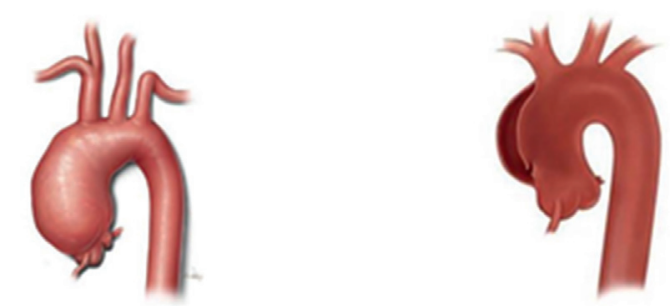

Patient presents with aortic aneurysm or aortic dissection and age $<60$ or $\geq 60$ without atherosclerosis or hypertension

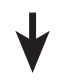

Aortic imaging and clinical evaluation of all first-degree relatives (parents, siblings, children)*
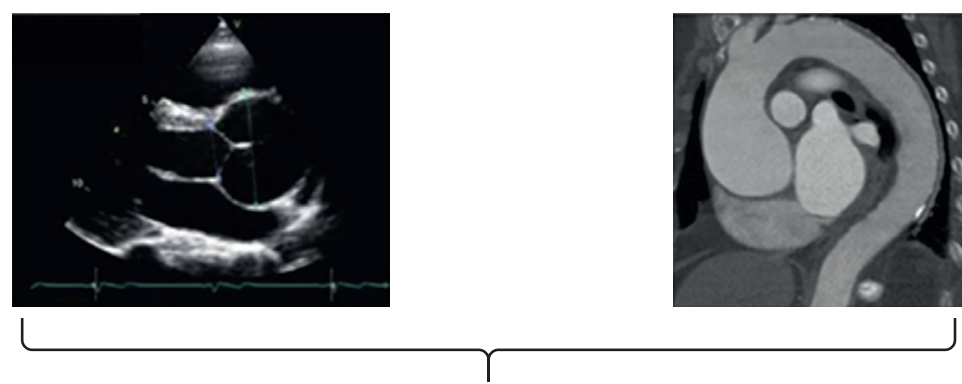

HTAD Present

Genetic Counseling and Testing
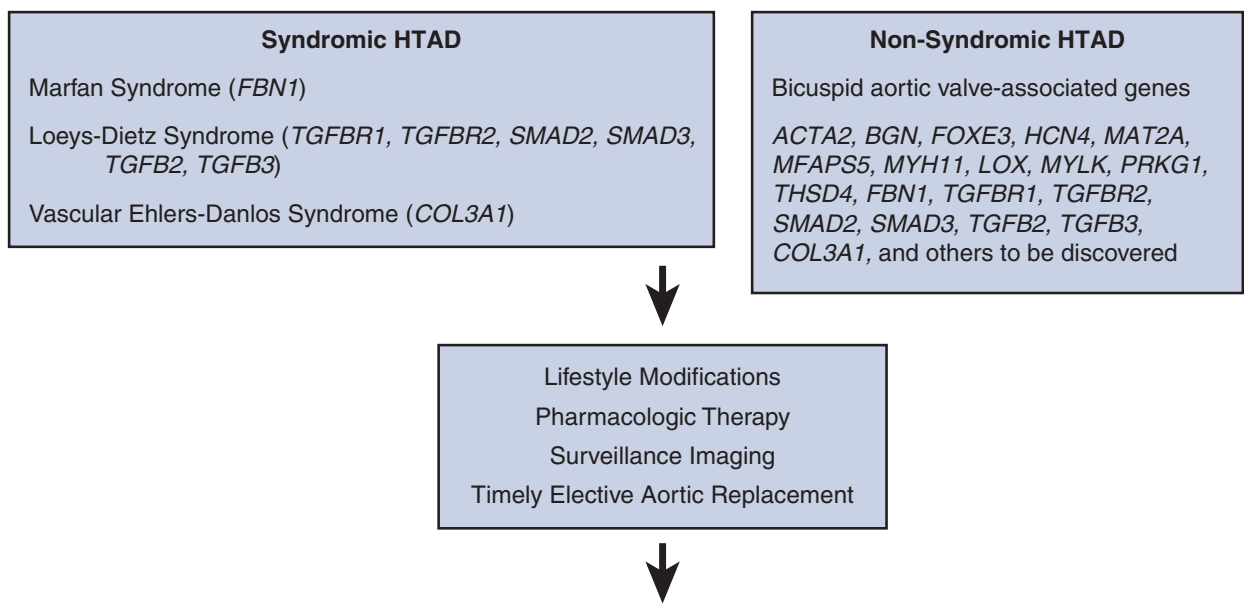

LIVES SAVED

${ }^{*}$ Re-evaluation in young $(<40)$ required when initial evaluation is negative and pathogenic variant is not identified in family.

FIGURE 1. Algorithm for family screening. HTAD, heritable thoracic aortic disease.

Medical management of patients with Loeys-Dietz syndrome is largely like that of Marfan syndrome, although similar randomized controlled trials of pharmacologic therapies have not been performed. The initial descriptions of the syndrome suggested a more aggressive aortic phenotype than that seen in Marfan syndrome; subsequent, more robust natural history data in patients harboring TGFBRI or TGFBR2 pathogenic variants led to the recommendation for elective root replacement at smaller diameters $(\leq 45 \mathrm{~mm}$ depending on gene, extra-aortic features, and sex). ${ }^{17}$ 
TABLE 1. Causal genes in hereditary thoracic aortic disease

\begin{tabular}{|c|c|}
\hline Gene & Related syndromic entity (when applicable) \\
\hline \multicolumn{2}{|l|}{ Genes encoding components of the extracellular matrix } \\
\hline COL $3 A 1$, procollagen type III $\alpha 1$ & Vascular Ehlers-Danlos syndrome \\
\hline$F B N 1$, fibrillin-1 & Marfan syndrome \\
\hline \multicolumn{2}{|l|}{$L O X$, lysyl oxidase } \\
\hline \multicolumn{2}{|l|}{$M F A P 5$, microfibrillar-associated protein 5} \\
\hline$B G N$, biglycan & Meester-Loeys syndrome \\
\hline \multicolumn{2}{|l|}{ THSD4, ADAMTS-like 6 protein } \\
\hline \multicolumn{2}{|l|}{ Genes encoding proteins involved in the TGF- $\beta$ pathway } \\
\hline TGFBR1, TGF- $\beta$ receptor type 1 & Loeys-Dietz syndrome \\
\hline \multicolumn{2}{|l|}{$T G F B R 2$, TGF- $\beta$ receptor type 2} \\
\hline \multicolumn{2}{|l|}{$\begin{array}{l}\text { SMAD2, Mothers against decapentaplegic Drosophila } \\
\text { homolog } 3\end{array}$} \\
\hline \multicolumn{2}{|l|}{$\begin{array}{l}\text { SMAD3, Mothers against decapentaplegic Drosophila } \\
\text { homolog } 3\end{array}$} \\
\hline \multicolumn{2}{|l|}{$T G F B 2$, TGF- $\beta 2$} \\
\hline \multicolumn{2}{|l|}{$T G F B 3$, TGF- $\beta 3$} \\
\hline$L T B P 3$, latent TGF- $\beta$-binding protein & Dental abnormalities and short stature \\
\hline \multicolumn{2}{|l|}{$\begin{array}{l}\text { Genes encoding components of the vascular smooth muscle } \\
\text { contractile apparatus }\end{array}$} \\
\hline ACTA2, SM $\alpha$-actin 2 & SM cell dysplasia syndrome \\
\hline \multicolumn{2}{|l|}{ MYH11, SM myosin heavy chain } \\
\hline \multicolumn{2}{|l|}{$M Y L K$, myosin light chain kinase } \\
\hline \multicolumn{2}{|l|}{$P R K G 1$, protein kinase cGMP-dependent type 1} \\
\hline \multicolumn{2}{|l|}{ Other genes } \\
\hline \multicolumn{2}{|l|}{ FOXE3, Forkhead box E3 } \\
\hline \multicolumn{2}{|l|}{ MAT2A, methionine adenosyltransferase II $\alpha$} \\
\hline $\begin{array}{l}H C N 4 \text {, hyperpolarization-activated cyclic nucleotide-gated } \\
\text { channel } 4\end{array}$ & HTAD with bradycardia and left ventricular noncompaction \\
\hline
\end{tabular}

The left column lists genes in italics with the proteins they encode. In the right column, syndromic entities are listed when applicable. Variants in practically all genes have been reported in patients with nonsyndromic HTAD. TGF, transforming growth factor; SM, smooth muscle; HTAD, hereditary thoracic aortic disease.

However, emerging data providing a more thorough description of the phenotypic spectrum of the different genotypes indicate that SMAD3 pathogenic variants are associated with a later onset of aortic dissections and elective surgeries compared to those with TGFBR1 or TGFBR2 variants. ${ }^{18}$

Vascular Ehlers-Danlos syndrome (VEDS), due to pathogenic variants in the collagen III gene (COL3A1), includes aortic aneurysm and dissection, as well as, more importantly and less predictably, nonaortic arterial aneurysms and dissections. ${ }^{19,20}$ Other typical features include hollow organ rupture (uterine, colonic) and spontaneous pneumothorax. Unfortunately, these phenotypic features may manifest as sudden catastrophes that prompt diagnosis, unless a family history is already known and family screening has been performed. Bedside clues to the underlying diagnosis include an almond-shaped facies with thin lips, translucent skin with easily visible venous patterns, easy bruising, and acrogeria (premature aging of the skin on hands and feet).
The vasodilating beta blocker celiprolol was shown to limit complications in a European population of VEDS patients. ${ }^{21}$ However, issues with study design have limited widespread acceptance of these findings, and a more rigorous treatment trial is needed. Owing to the unpredictable progression of vascular disease, as well as technical difficulties associated with surgical repair, surveillance imaging is critical, with surgical interventions generally tailored to individual circumstances.

Identification of underlying genetic variants allows further classification based on putative pathogenic mechanisms for both syndromic and nonsyndromic conditions (Table 1). ${ }^{6,8,22}$ Over the past 2 decades, the genetic underpinnings of nonsyndromic HTAD have been identified, and their natural and clinical histories are in the process of more robust characterization. Of note, the pathogenic variants associated with syndromic conditions also may be causative of aortic disease in nonsyndromic as well as sporadic HTAD. ${ }^{22,23}$ Current commercially available genetic aortopathy panels screen for most pathogenic variants discussed in 
TABLE 2. Syndromic hereditary thoracic aortic diseases

\begin{tabular}{|c|c|c|}
\hline Disease & Gene(s) & Diagnosis/phenotypic features* \\
\hline Marfan syndrome & FBN1 & $\begin{array}{l}\text { Aortic root aneurysm } \\
\text { Ectopia lentis* } \\
\text { Systemic score ( } \geq 7 \text { required for cardinal feature): arachnodactyly (3); pectus carinatum, hind foot } \\
\text { deformity, spontaneous pneumothorax, dural ectasia (all 2); scoliosis or kyphosis, reduced } \\
\text { elbow extension, pes planus, striae, dolichocephaly, pectus excavatum, severe myopia, } \\
\text { mitral prolapse (all 1) }\end{array}$ \\
\hline Loeys-Dietz syndrome & $\begin{array}{l}\text { TGFBR1 } \\
\text { TGFBR2 } \\
\text { SMAD2 } \\
\text { SMAD3 } \\
\text { TGFB2 } \\
\text { TGFB3 }\end{array}$ & $\begin{array}{l}\text { Aortic root aneurysm } \\
\text { Similar systemic features, as above, other than ectopia lentis } \\
\text { Cleft palate, bifid uvula* } \\
\text { Clubfoot* } \\
\text { Hypertelorism* }\end{array}$ \\
\hline $\begin{array}{l}\text { Vascular Ehlers-Danlos } \\
\text { syndrome }\end{array}$ & COL3A1 & $\begin{array}{l}\text { Medium-sized artery aneurysms and dissections* } \\
\text { Hollow organ rupture: uterus, colon* } \\
\text { Spontaneous pneumothorax } \\
\text { Skin: translucent, easy bruising, acrogeria* }\end{array}$ \\
\hline
\end{tabular}

*Indicates those features that are relatively specific to the syndrome (ie, nonoverlapping)

this article; however, as many as $70 \%$ to $80 \%$ of families with HTAD will not have a known pathogenic variant. ${ }^{4,6}$

Bicuspid aortic valve (BAV) is commonly associated with aortic aneurysm and is hereditary in a small percentage $(<10 \%)$, with first-degree relatives exhibiting BAV and/or aortic aneurysm. ${ }^{24}$ Interestingly, male family members are more likely than female family members to have BAV, similar to the male predominance of BAV in general. Genes associated with BAV include some specific genes (NOTCH1, GATA5, SMAD6, LOX, ROBO4, and TBX20), in addition to genes related to HTAD (TGFBR1, TGFBR2, TGFB2, TGFB3, ACTA2, and MAT2A).

Patients with pathogenic variants in the ACTA2 gene affecting smooth muscle integrity frequently present with acute aortic dissection. ${ }^{5}$ Lysyl oxidases are involved in cross-linking of elastin and collagen fibers; pathogenic variants in the $L O X$ gene have been found to cause aortic root fusiform aneurysms extending to the ascending aorta and dissections of the ascending but not the descending aorta. ${ }^{25}$ Individuals with pathogenic variants in the gene encoding myosin light chain kinase $(M Y L K)$ frequently present with aortic dissection, because clues to an underlying aortopathy are not present. Although not all affected family members have aortic aneurysms, aortic size following dissection is not always enlarged, making management decisions for elective aortic surgery complicated. $^{26}$

Families in whom HTAD is identified require multidisciplinary teams for optimal care. For example, conditions such as Marfan syndrome require coordinated care between ophthalmology, orthopedics, pediatrics, rehabilitation medicine, and maternal-fetal medicine, in addition to cardiology and cardiothoracic surgery. Vascular surgeons are a critical part of the team managing VEDS patients. Genetic counseling is important for all families with HTAD, especially in the context of family planning. In addition, genetic counselors will aid the interpretation of genetic testing results. Although known pathogenic variants are relatively straightforward, a negative study or variant of uncertain significance (VUS) requires additional discussion. ${ }^{27}$ Gene discovery is ongoing, and pathogenic variants may be identified in the future in certain families, necessitating a strategy for retesting. A VUS in HTAD genes is found more frequently in HTAD families, ${ }^{6}$ suggesting that some variants should ultimately be reclassified when disease association is confirmed.

Preventive screening for HTAD usually applies to specific clinical situations, as discussed above. However, thanks to technical progress in genetic testing, leading to a much higher throughput at lower costs, screening strategies at the population level are being undertaken. The creation of large biobanks offers the potential to set up largescale genetic screening in populations whose clinical phenotype will be less well defined. This strategy is also called the "genotype-first" approach. Care needs to be taken with ethical issues, and people need to be informed appropriately. Results from studies applying this approach have already indicated utility in the identification of undiagnosed cases of Marfan syndrome, the ultimate goal in preventing potentially lethal complications. ${ }^{28}$

Taking population genetics even further, genome-wide association study results, combined with large aortic imaging datasets, can be used to design polygenic risk scores. These may enable the identification of even larger groups of asymptomatic individuals at risk for aneurysm or dissection and also facilitate the prioritization of potential 
TABLE 3. Knowledge gaps in hereditary thoracic aortic diseases

- The underlying genotype is unknown for the vast majority of nonsyndromic hereditary thoracic aortic diseases.

- The full spectrum of natural and clinical histories is lacking.

- Randomized controlled trials of pharmacologic therapies are lacking in non-Marfan conditions.

- Imaging strategies based on natural histories of various conditions need to be devised.

- Thresholds for elective aortic replacement surgery need to be established based on dissection risk in different genotypes.

- Refinement of techniques is needed to avoid significant aortic regurgitation following valve-sparing root replacement.

- Causes of type B dissection following elective ascending aortic surgery need to be elucidated.

therapeutic targets for the prevention or treatment of aortic aneurysm. $^{29}$

Although major advances have been made in the identification, classification, and treatment of individuals with HTAD, important knowledge gaps remain that inform ongoing and needed research (Table 3). Gene discovery is required for the vast majority of families with aortic aneurysms. Robust characterization of the disease spectrum based on genotype, particularly in the nonsyndromic conditions, requires pooling of resources to achieve large-sized cohorts. Randomized controlled trials of pharmacologic therapies in non-Marfan populations should be performed. Optimal strategies for surveillance imaging, particularly in vascular Ehlers-Danlos syndrome and Loeys-Dietz syndrome, need to be justified. Pregnancy risks in women with differing mutations require further investigation. Thresholds for elective surgical interventions need to be refined based on dissection risk by genotype. Although valvesparing root replacement is proving to be a durable procedure in skilled hands, the long-term development of significant aortic regurgitation remains a concern, as does the appreciable occurrence of type B aortic dissection in those with genetic aortopathies. ${ }^{3}$

In conclusion, major strides have been made in defining the genetic and molecular bases of HTAD over the past several decades. Refinements in surgical techniques have resulted in a lower risk:benefit ratio that permits elective aortic replacement at lower thresholds to further lessen the risk of aortic dissection. Nevertheless, early detection of aneurysms before dissection, particularly in nonsyndromic conditions, remains a public health priority. To this end, family history is a powerful tool. Aggressive screening of first-degree relatives resulting in early disease detection inarguably saves lives.

\section{Conflict of Interest Statement}

The authors reported no conflicts of interest.

The Journal policy requires editors and reviewers to disclose conflicts of interest and to decline handling or reviewing manuscripts for which they may have a conflict of interest. The editors and reviewers of this article have no conflicts of interest.

\section{References}

1. Huynh N, Thordsen S, Thomas T, Mackey-Bojack SM, Duncanson ER, Nwuado D, et al. Clinical and pathologic findings of aortic dissection at autopsy: review of 336 cases over nearly 6 decades. Am Heart J. 2019;209:108-15.

2. Chen SW, Kuo CF, Huang YT, Lin WT, Wu VCC, Chou AH, et al. Association of family history with incidence and outcomes of aortic dissection. J Am Coll Cardiol. 2020;76:1181-92.

3. Raunsø J, Song RJ, Vasan RS, Bourdillon MT, Nørager B, Torp-Pederson C, et al Familial clustering of aortic size, aneurysms, and dissections in the community Circulation. 2020;142:920-8.

4. Sherrah AG, Andvik S, van der Linde D, Davies L, Bannon PG, Padang R, et al. Nonsyndromic thoracic aortic aneurysm and dissection: outcomes with Marfan syndrome versus bicuspid aortic valve aneurysm. J Am Coll Cardiol. 2016;67: 618-26.

5. Regalado ES, Guo DC, Prakash S, Bensend TA, Flynn K, Estrera A, et al. Aortic disease presentation and outcome associated with ACTA2 mutations. Circ Cardiovasc Genet. 2015;8:457-64.

6. Pinard A, Jones GT, Milewicz DM. Genetics of thoracic and abdominal aortic diseases. Circ Res. 2019;124:588-606.

7. Gray JR, Bridges AB, Faed MJ, Pringle T, Baines P, Dean J, et al. Ascertainment and severity of Marfan syndrome in a Scottish population. J Med Genet. 1994;31: 51-4.

8. Verhagen JMA, Kempers M, Cozijnsen L, Bouma BJ, Duijhouwer AL, Post JG, et al. Expert consensus recommendations on the cardiogenetic care for patients with thoracic aortic disease and their first-degree relatives. Int J Cardiol. 2018; 258:243-8.

9. Loeys BL, Dietz HC, Braverman AC, Callewaert BL, De Backer J, Devereux RB, et al. The revised Ghent nosology for the Marfan syndrome. J Med Genet. 2010; 47:476-85.

10. Lacro RV, Dietz HC, Sleeper LA, Yetman AT, Bradley TJ, Colan SD, et al; for the Pediatric Heart Network Investigators. Atenolol versus losartan in children and young adults with Marfan syndrome. $N$ Engl J Med. 2014;371:2061-71.

11. Milleron O, Arnout F, Delorme G, Detaint D, Pellenc Q, Raffoul R, et al. Pathogenic FBN1 genetic variation and aortic dissection in patients with Marfan syndrome. J Am Coll Cardiol. 2020;75:843-53.

12. Roman MJ, Devereux RB, Preiss LR, Asch FM, Eagle KA, Holmes KW, et al; for the GenTAC Investigators. Associations of age and sex with Marfan phenotype: the NHLBI GenTAC Registry. Circ Cardiovasc Genet. 2017;10:e001647.

13. Franken R, Teixido-Tura G, Brion M, Forteza A, Rodriguez-Palomares J, Gutierrez L, et al. Relationship between fibrillin-1 genotype and severity of cardiovascular involvement in Marfan syndrome. Heart. 2017;103:1795-9.

14. Loeys BL, Chen J, Neptune ER, Judge DP, Podowski M, Holm T, et al. A syndrome of altered cardiovascular, craniofacial, neurocognitive and skeletal development caused by mutations in TGFBR1 or TGFBR2. Nat Genet. 2005;37: 275-81.

15. Schepers D, Tortora G, Morisaki H, MacCarrick G, Lindsay M, Liang D, et al. A mutation update on the LDS-associated genes TGFB2/3 and SMAD 2/3. Hum Mutat. 2018;39:621-34.

16. van de Laar IMBH, Oldenburg RA, Pals G, Roos-Hesselink JW, de Graaf BM, Verhagen JMA, et al. Mutations in SMAD3 cause a syndromic form of aortic aneurysms and dissections with early-onset osteoarthritis. Nat Genet. 2011;43: 121-6.

17. Jondeau G, Ropers J, Regelado E, Braverman A, Evangelista A, Teixedo G, et al; for the Montalcino Aortic Consortium. International registry of patients carrying TGFBR1 or TGFBR2 mutations: results of the MAC (Montalcino Aortic Consortium). Circ Cardiovasc Genet. 2016;9:548-58. 
18. Hostetler EM, Regalado ES, Guo DC, Hanna N, Arnaud P, Muiño-Mosquera L, et al. SMAD3 pathogenic variants: risk for thoracic aortic disease and associated complications from the Montalcino Aortic Consortium. J Med Genet. 2019;56: 252-60.

19. Pepin M, Schwarze U, Superti-Furga A, Byers PH. Clinical and genetic features of Ehlers-Danlos syndrome type IV, the vascular type. N Engl J Med. 2000;342: 673-80.

20. Pepin MG, Schwarze U, Rice KM, Liu M, Leistritz D, Byers PH. Survival is affected by mutation type and molecular mechanism in vascular Ehlers-Danlos syndrome (EDS type IV). Genet Med. 2014;16:881-8.

21. Ong KT, Perdu J, De Backer J, Bozec E, Collignon P, Emmerich J, et al. Effect of celiprolol on prevention of cardiovascular events in vascular Ehlers-Danlos syndrome: a prospective randomised, open, blinded-endpoints trial. Lancet. 2010; 376:1476-84.

22. Renard M, Francis C, Ghosh R, Scott AF, Witmer PD, Adès LC, et al. Clinical validity of genes for heritable thoracic aortic aneurysm and dissection. $J$ Am Coll Cardiol. 2018;72:605-15.

23. Guo DC, Hostetler EM, Fan Y, Kulmacz RJ, Zhang D, GenTAC Investigators, et al. Heritable thoracic aortic disease genes in sporadic aortic dissection. J Am Coll Cardiol. 2017;70:2728-30.

24. Galian-Gay L, Hevia AC, Teixedo-Turà G, Palomares JR, GutiérrezMoreno L, Maldonado G, et al. Familial clustering of bicuspid aortic valve and its relationship with aortic dilation in first-degree relatives. Heart. 2019; 105:603-8
25. Guo DC, Regalado ES, Gong L, Duan X, Santos-Cortez RLP, Arnaud P, et al LOX mutations predispose to thoracic aortic aneurysms and dissections. Circ Res. 2016;118:928-34.

26. Wallace SE, Regalado ES, Gong L, Janda AL, Guo DC, Russo CF, et al. MYLK pathogenic variants aortic disease presentation, pregnancy risk, and characterization of pathogenic missense variants. Genet Med. 2019;21:144-51.

27. Musunuru K, Hershberger RE, Day JM, Klinedinst NJ, Landstrom AP, Parikh VN, et al. Genetic testing for inherited cardiovascular diseases: a scientific statement from the American Heart Association. Circ Genom Precis Med. 2020 13:e000067.

28. Wenger BM, Patel N, Lui M, Moscati A, Do R, Stewart DR, et al. A genotypefirst approach to exploring Mendelian cardiovascular traits with clear external manifestations. Genet Med. 2021;23:94-102.

29. Pirruccello JP, Chaffin MD, Fleming SJ, Arduini A, Lin H, Khurshid S, et al. Deep learning enables genetic analysis of the human thoracic aorta [preprint]. BioRxiv. Available at: https://www.biorxiv.org/content/10.1101/2020.05.12.091934v1. Accessed February 19, 2021.

30. David TE, David CM, Ouzounian M, Feindel CM, Lafreniere-Roula M. A progress report on reimplantation of the aortic valve. J Thorac Cardiovasc Surg. September 5, 2020 [Epub ahead of print].

Key Words: aortic aneurysm, aortic dissection, heritable aortic disease 